\title{
Vocabulary knowledge: Malaysian tertiary level learners' major problem in summary writing
}

\begin{abstract}
The ability to summarize and paraphrase written pieces is one of the essential skills tertiary level students need in order to succeed in their academic endeavor. It involves the process of decoding a text, and then re-encoding it by making changes to the structure and vocabulary of the original text while maintaining its content. The present study analyzes a group of tertiary level students' written samples to diagnose their main areas of difficulty in writing business report summaries. For this purpose, a sample of 69 samples was collected from an intact group of learners. Two raters used an analytic writing scale to score the samples individually. Based on the results, majority of the students (about 70\%) achieved 'excellent to very good' scores for the 'content' of their written samples. However, regarding the 'organization' and 'vocabulary' of their written pieces, respectively $75 \%$ and $97 \%$ of these students scored 'Fair to poor'. 'Good to average' results were achieved for a majority of the students' 'language use' and 'mechanics' skills. The findings of the present study accentuate the urgent need for remedy courses to help these students improve their organization and vocabulary skills in ESL writing. Further research is necessary to diagnose the learners' difficulty areas in other genres of writing such as argumentative and narrative modes.
\end{abstract}

